УДК $544.4+544.342$

\title{
ВЛИЯНИЕ ВЫСОКОЧАСТОТНОГО ЭЛЕКТРОМАГНИТНОГО ПОЛЯ НА МУТАРОТАЦИЮ ВОДНЫХ РАСТВОРОВ ГЛЮКОЗЫ И ФРУКТОЗЫ
}

\author{
(C) Б.П. Шипунов ${ }^{* *}$, А.В. Рябых
}

Алтайский государственный университет, пр. Ленина, 61, Барнаул, 656049

(Россия), e-mail: sbp@mc.asu.ru

\footnotetext{
* Полный текст статьи опубликован: Шипунов Б.П., Рябых А.В. Влияние высокочастотного электромагнитного поля на мутаротацию водных растворов глюкозы и фруктозы // Химия растительного сырья. 2019. №3. С.235-240. DOI: $10.14258 /$ jcprm. 2019034456.

** Автор, с которым следует вести переписку.
} 
Таблица 1. Изменение удельного вращения глюкозы во времени

\begin{tabular}{c|c|c|c|c|c|c|c|c}
\hline \multirow{2}{*}{ Время, мин } & \multicolumn{7}{|c}{ Углы вращения при соответствующих частотах полевой предобработки, МГц } \\
\cline { 2 - 9 } & 0 & 30 & 60 & 90 & 110 & 140 & 170 & 200 \\
\hline 3 & 98.0 & 100.2 & 99.2 & 99.8 & 102.4 & 100.9 & 102.0 & 100.9 \\
4 & 94.1 & 92.8 & 95.2 & 98.6 & 97.4 & 94.6 & 100.9 & 99.8 \\
5 & 91.2 & 91.7 & 95.2 & 97.8 & 93.5 & 89.5 & 96.9 & 97.5 \\
6 & 86.6 & 87.1 & 89.5 & 92.3 & 91.3 & 89.5 & 93.5 & 94.6 \\
7 & 84.9 & 85.4 & 85.5 & 91.2 & 88.6 & 86.6 & 90.1 & 91.8 \\
8 & 80.9 & 81.4 & 80.9 & 86.6 & 88.4 & 85.5 & 87.8 & 88.4 \\
9 & 78.1 & 78.7 & 80.9 & 86.4 & 86.0 & 83.8 & 87.2 & 87.8 \\
10 & 75.8 & 75.2 & 78.1 & 83.2 & 81.4 & 80.9 & 83.2 & 84.4 \\
15 & 67.8 & 67.3 & 69.5 & 74.1 & 70.8 & 75.2 & 73.0 & 75.2 \\
20 & 59.3 & 62.1 & 62.7 & 69.0 & 68.1 & 63.8 & 66.7 & 69.0 \\
25 & 58.7 & 58.4 & 61.6 & 64.4 & 66.9 & 61.6 & 63.8 & 62.7 \\
\hline
\end{tabular}

Конечные углы вращения растворов составили 52.5․ Для частот 140, 170 и 200 МГц время старта измерений составило не 2.5, а 3 мин. В таблице 1 представлены рассчитанные по формулам 2 и 3 значения условных констант процесса мутаротации.

Таблица 2. Средние значения констант скорости реакции мутаротации D-глюкозы

\begin{tabular}{c|c|c|c|c|c|c|c|c}
\hline Частота, МГц & 0 & 30 & 60 & 90 & 110 & 140 & 170 & 200 \\
\hline$<\mathrm{k}>$, мин-1 & $0.074 \pm 0.01$ & $0.070 \pm 0.012$ & $0.064 \pm 0.009$ & $0.049 \pm 0.006$ & $0.049 \pm 0.011$ & $0.062 \pm 0.008$ & $0.048 \pm 0.009$ & $0.047 \pm 0.008$ \\
\hline
\end{tabular}

Таблица 3. Расчетные условные константы мутаротации

\begin{tabular}{c|c|c|c|c|c|c|c|c}
\hline \multirow{2}{*}{ Время } & \multicolumn{7}{|c}{ Значения условных констант скорости во времени для различных частот полевой предобработки } \\
\cline { 2 - 8 } & 0 & 30 & 60 & 90 & 110 & 140 & 170 & 200 \\
\hline 2.5 & 0.0450 & 0.0316 & 0.0403 & 0.0403 & 0.0108 & - & - & - \\
3 & 0.0538 & 0.0381 & 0.0455 & 0.0415 & 0.0237 & 0.0336 & 0.0258 & 0.0336 \\
4 & 0.0632 & 0.0706 & 0.0565 & 0.0372 & 0.0438 & 0.0598 & 0.0252 & 0.0311 \\
5 & 0.0648 & 0.0622 & 0.0452 & 0.0335 & 0.0531 & 0.0738 & 0.0373 & 0.0348 \\
6 & 0.0748 & 0.0724 & 0.0615 & 0.0491 & 0.0535 & 0.0615 & 0.0444 & 0.0399 \\
7 & 0.0715 & 0.0693 & 0.0690 & 0.0463 & 0.0564 & 0.0641 & 0.0505 & 0.0442 \\
8 & 0.0789 & 0.0767 & 0.0789 & 0.0561 & 0.0501 & 0.0604 & 0.0520 & 0.0500 \\
9 & 0.0819 & 0.0797 & 0.0701 & 0.0508 & 0.0523 & 0.0596 & 0.0481 & 0.0462 \\
10 & 0.0823 & 0.0857 & 0.0737 & 0.0554 & 0.0617 & 0.0631 & 0.0554 & 0.0518 \\
15 & 0.0832 & 0.0859 & 0.0761 & 0.0604 & 0.0713 & 0.0570 & 0.0640 & 0.0570 \\
20 & 0.103 & 0.0857 & 0.0827 & 0.0588 & 0.0616 & 0.0774 & 0.0662 & 0.0588 \\
25 & 0.0858 & 0.0826 & 0.0708 & 0.0600 & 0.0522 & 0.0708 & 0.0619 & 0.0661 \\
$<\mathrm{k}>$, мин $^{-1}$ & $0.074 \pm 0.01$ & $0.070 \pm 0.012$ & $0.064 \pm 0.009$ & $0.049 \pm 0.06$ & $0.049 \pm 0.011$ & $0.062 \pm 0.008$ & $0.048 \pm 0.009$ & $0.047 \pm 0.008$ \\
\hline
\end{tabular}

Таблица 4. Зависимость равновесного удельного вращения фруктозы от времени*

\begin{tabular}{c|c|c|c|c|c}
\hline Время, сутки & Угол, 0 & Угол, 30 МГц & Угол, 60 МГц & Угол, 90 МГц & Угол, 170 МГц \\
\hline 0 & -87.5 & -87.5 & -87.5 & -87.5 & -88 \\
2 & -87.5 & -87.5 & -88.5 & -87.5 & -88 \\
4 & -87.5 & -87.5 & -88.5 & -87.5 & -89 \\
5 & -87.5 & -87.5 & -89.5 & -89 & -89.5 \\
6 & -88 & -87.5 & -89.5 & -89.5 & -89.5 \\
12 & -87.5 & -87.5 & -89.5 & -90 & -89.5 \\
15 & -87.5 & -87.5 & -89 & -90 & -92 \\
25 & -89.5 & -88 & -89.5 & -91.5 & -93.5 \\
30 & -89.5 & -89.5 & -90 & \\
\hline
\end{tabular}

\footnotetext{
${ }^{*}$ Температура окружающего воздуха контролировалась за весь период измерений $\left(25 \pm 2^{\circ} \mathrm{C}\right)$.
} 